\title{
RESPOSTAS FISIOLÓGICAS DE DENDÊ SUBMETIDAS AO ESTRESSE HÍDRICO EM CONDIÇÕES DO CERRADO
}

\author{
Sérgio José da Costa ${ }^{1}$, Eduardo Andrea Lemus Erasmo ${ }^{2}$, Taynar Coelho de Oliveira Tavares2, Joedna \\ Silva ${ }^{1}$
}

\begin{abstract}
RESUMO - Avaliou-se o desempenho de quatro híbridos de dendê sob estresse hídrico e irrigados em condições de cerrado. As variáveis consideradas em todos os materiais foram a fotossíntese líquida (A), os valores de transpiração (E), a condutância estomática (gs), a concentração de carbono interno (Ci) e a eficiência do uso da água $\left(\mathrm{A} \mathrm{E}^{-1}\right)$. Os cinco híbridos avaliados reduziram drasticamente a fotossíntese líquida sob condição de estresse hídrico. O BRS Manicoré e o BRS 2001 apresentaram redução drástica na condutância estomática. Para o balanço de carbono (Ci) os valores sugeriram que a manutenção de concentrações internas de $\mathrm{CO}_{2}$ foram relativamente altas sob estresse em todos os materiais, sendo o BRS $2001 \mathrm{com}$ maior Ci, entretanto este mesmo material apresentou menor eficiência no uso da água. As plantas de dendê (Elaeis guineensis) apresentaram baixa tolerância à deficiência hídrica nos solos de cerrado, entretanto nas condições que foi desenvolvido o trabalho pode se considerar que os híbridos BRS 2501 e BRS 2528, foram os mais eficientes fisiologicamente nas condições de estresse hídrico.
\end{abstract}

Palavras chave: Elaeis Guineensis, manejo hídrico, Tocantins.

\section{PHYSIOLOGICAL RESPONSES OF DENDÊ SUBMITTED TO WATER STRESS IN CERRADO CONDITIONS}

\begin{abstract}
Evaluated were the performance of four hybrid palm the tested conditions imposed were under water and irrigated stress in cerrado conditions The following parameters were considered: photosynthesis (A), transpiration values (E), stomatal conductance ( $g s$ ), internal carbon concentration (Ci) and efficiency of water use $\left(E^{-1}\right)$. The five hybrids drastically reduced the net photosynthesis under water stress conditions. The Manicoré BRS and the BRS 2001 showed drastic reduction in stomatal conductance. For the carbon balance (Ci) values suggest that the maintenance of internal $\mathrm{CO}_{2}$ concentrations were relatively high under stress in all materials. Where BRS 2001 showed the highest Ci. However this same material showed the lowest efficient in water use. The materials BRS C2501 and BRS Manicore showed higher efficiency. The plant Dendê (Elaeis guineensis) showed low tolerance to water stress in cerrado soils, however in conditions that the study was carried out, it can be considered that the BRS 2501 and BRS 2528 hybrid were the most efficient physiologically in water stress conditions.
\end{abstract}

Keywords: Elaeis Guineensis, Tocantins, water management.

\footnotetext{
${ }^{1} 1$ Instituto Federal de Educação, Ciência e Tecnologia do Tocantins (IFTO), Campus de Gurupi, Gurupi, TO, Brasil. sergiojose@ifto.edu.br; joedna.silva@ifto.edu.br.

${ }^{2}$ Universidade Federal do Tocantins (UFT), Campus de Gurupi, Gurupi, TO, Brasil. erasmolemus@mail.uft.edu.br *Contato para correspondência: taynar@uft.edu.br
} 


\section{INTRODUÇÃO}

O dendê (Elaeis Guineensis), originário da África Ocidental é uma cultura que produz maior quantidade de óleo por unidade de área cultivada entre todas as outras plantas oleaginosas no Brasil, com uma produtividade média de 4 toneladas de óleo/ha/ano, cerca de 10 vezes maior que a produtividade da soja. Além disso, o ciclo produtivo pode ocorrer durante um período de 25 a 30 anos, sendo uma espécie de elevado capacidade de realizar sequestro de carbono e pode ser usado como reflorestamento de áreas degradadas, além de ter uma participação efetiva no Movimento de Desenvolvimento Limpo (CDM) com a venda de créditos de carbono (Queiroz et al., 2012).

A localização geográfica, as condições climáticas, a disponibilidade de energia solar e as condições tecnológicas destacam a aptidão do Brasil para a expansão da produção dessa energia renovável. Especificamente para a cultura do dendê, o estado do Pará é o líder brasileiro na produção de derivados desta planta, correspondendo cerca de $95 \%$ da produção nacional, seguido pelo estado da Bahia que é responsáveis pela produção dos 5\% restante (Queiroz et al., 2012).

O Tocantins, Estado que apresenta vocação econômica voltada para o agronegócio, vem despontando como forte e promissora fronteira agrícola do país, com solos aptos para seu cultivo. Entretanto, apresenta regime pluviométrico como sendo o principal gargalo para o estabelecimento desta cultura.

Por outro lado, o dendezeiro apresenta potencial, tanto na abrangência de seu uso, como em estudos no melhoramento genético. Assim, algumas conquistas já foram realizadas, como o desenvolvimento de variedades mais produtivas e a descoberta de materiais com maior resistência a doenças e outras características de interesse que podem fazer com que essa cultura se desenvolva no estado do Tocantins. O dendê vem sendo estudado por diversos autores em vários locais do país (Azevedo et al., 2008; Chia et al., 2009; Texeira et al., 2009; Maciel et al., 2011; Chia et al., 2012; Moura et al., 2013; Gomes Junior et al., 2017).

Entre os fatores abióticos, Taiz \& Zeiger (2009) justificam que embora as plantas, em geral, possuam níveis múltiplos de controle sobre a fotossíntese, além de luz e temperatura, a produçao de fotoassimiados pode alterado em plantas com estresse hidrico. Assim, o déficit hídrico pode ser um dos principais responsáveis por acarretar reduções na produtividade agrícola, o que deve ser contornado, pois um dos fatores ambientais que comprometer praticamente todos os aspectos relacionados ao desenvolvimento das plantas do coqueiro é o estresse hídrico (Passos et al., 2006).

Segundo Nogueira et al. (2001) ressaltam que o ideal é que sejam analisados um conjunto de variáveis, tais como a fotossíntese (A), a condutância estomática (gs), a transpiração foliar (E), a concentração interna de $\mathrm{CO} 2(\mathrm{Ci})$ e a eficiência instantânea do uso da água $\left(\mathrm{E}^{-1}\right)$ que são coletivamente considerados indicativos do desempenho dos vegetais diante do estresse hídrico.

Neste contexto, o estudo buscou avaliar as respostas fisiológicas de quatro híbridos de dendê tipo tenera (BRS 2501, BRS 7201, BRS 2001 e BRS 2528) e um de Caiaué (BRS Manicoré), submetidos a regimes de déficit hídrico, visando identificar os mais eficientes às condições de cerrado do Tocantins.

\section{MATERIAL E MÉTODOS}

O trabalho foi conduzido na Estação Experimental de Pesquisa do Campus Universitário de Gurupi, pertencente à Universidade Federal do Tocantins - UFT, localizado à latitude $11^{\circ} 43^{\prime} 00^{\prime \prime} \mathrm{S}$ e longitude $49^{\circ} 04^{\prime}$ $00^{\prime \prime} \mathrm{W}$, em altitude média de $287 \mathrm{~m}$. A temperatura média anual local é de, aproximadamente, $26^{\circ} \mathrm{C}$, estando a umidade relativa do ar em torno de $56,1 \%$ e a precipitação acumulada foi de $1.318,1 \mathrm{~mm}$ durante a condução do experimento.

O solo é caracterizado como Latossolo Amarelo Distrófico típico. As amostras simples de solo foram coletadas em técnicas de ziguezague, em duas profundidades: $0-20 \mathrm{~cm}$ e $20-40 \mathrm{~cm}$, com auxílio de trado holandês. $\mathrm{O}$ solo apresentou as seguintes características: $\mathrm{pH}\left(\mathrm{CaCl}_{2}\right)=4,5 ; \mathrm{P}=1,3 \mathrm{mg} \mathrm{dm}^{-3}, \mathrm{~K}=21 \mathrm{mg} \mathrm{dm}^{-3}, \mathrm{Ca}$ $=1,6 \mathrm{cmol}_{\mathrm{c}} \mathrm{dm}^{-3}, \mathrm{Mg}=1,3 \mathrm{cmol}_{\mathrm{c}} \mathrm{dm}^{-3}, \mathrm{Al}=0,0 \mathrm{cmol}_{\mathrm{c}}$ $\mathrm{dm}^{-3}, \mathrm{H}+\mathrm{Al}=2,8 \mathrm{cmol}_{\mathrm{c}} \mathrm{dm}^{-3}, \mathrm{CTC}$ total $=5,75 \mathrm{cmol}_{\mathrm{c}}$ $\mathrm{dm}^{-3}$, matéria orgânica $=1,8 \%$, areia $=56 \%$, silte $=13 \%$ e argila $=31 \%$ na profundidade de 0 a 20 . E para 20 - 40 o solo apresentou: $\mathrm{pH}(\mathrm{CaCl} 2)=4,4, \mathrm{P}=2,7 \mathrm{mg}$ $\mathrm{dm}^{-3}, \mathrm{~K}=46,0 \mathrm{mg} \mathrm{dm}^{-3}, \mathrm{Ca}=0,5 \mathrm{cmol}_{\mathrm{c}} \mathrm{dm}^{-3}, \mathrm{Mg}=0,4 \mathrm{cmol}_{\mathrm{c}}$ $\mathrm{dm}^{-3}, \mathrm{Al}=0,20 \mathrm{cmol}_{\mathrm{c}} \mathrm{dm}^{-3}, \mathrm{H}+\mathrm{Al}=3,10 \mathrm{cmol}_{\mathrm{c}} \mathrm{dm}^{-3}, \mathrm{CTC}$ total $=4,12 \mathrm{cmol}_{\mathrm{c}} \mathrm{dm}^{-3}$, matéria orgânica $=1,6 \%$, areia $=66,9 \%$, silte $=3,8 \%$ e argila $=29,3 \%$. 
O preparo da área foi realizado de agosto a novembro de 2014, com calcário dolomítico aplicado em faixas, equivalente a 1,5 t/ha, em agosto de 2014. As sementes pré-germinadas de dendezeiro tipo tenera (Elaeis guineenses Jacq.), variedades BRS 2501, BRS 2001, BRS 2528 e BRS 7201 e um Caiaué (Elaeis guineenses) variedade BRS Manicoré foram fornecidas pela Embrapa Amazônia Ocidental. A produção das mudas foi feita com 3 meses de pré-viveiro e 7 meses de viveiro.

O plantio das mudas de dendezeiro foi realizado em novembro de 2014, com área total do experimento de 01 hectare, obedecendo ao arranjo espacial triangular equilátero de 9,0 m x 9,0 m x 9,0m, entre as plantas, totalizando 143 plantas/ha. As covas de plantio foram abertas medindo $0,4 \mathrm{~m}$ de largura e $0,4 \mathrm{~m}$ de profundidade.

No momento do plantio foi feita a adubação com fosfato natural com aplicação por cova de $300 \mathrm{~g}$ de $\mathrm{P}_{2} \mathrm{O}_{5}$, sendo o fosfato natural de Gafsa como fonte. Em dezembro foi feita adução de cobertura do $\mathrm{N}, \mathrm{P}_{2} \mathrm{O}_{5}$, $\mathrm{K}, \mathrm{Mg}$ e B nas quantidades de 70,0;120,0;60,0;9,0 e 3,0g respectivamente/ planta.

Quando as plantas atingiram 12 meses em campo, passaram um período de um mês sem irrigação, e nesta condição foram medidas as variáveis fisiológicas nas plantas e posteriormente, logo após as leituras, foi feita irrigação por 20 dias com volume de 30 litros de água para cada planta/dia. Após este período foram coletados novos dados das variáveis fisiológicas, sendo selecionadas para cada híbrido 04 plantas. Nestas plantas foi utilizada a folha $\mathrm{n}^{\circ} 9$, como folha padrão de coleta dos dados. Sendo estes coletados no horário compreendido entre as 14:00 e 14:10 horas, por se tratar de horário com maior radiação solar e os testes de comportamento diário demonstrarem que os materiais genéticos apresentam resultados com ligeiros picos para os parâmetros avaliados (Figura 1).

Para a coleta das variáveis fisiológicas foi utilizado um analisador de gases infravermelho portátil (Irga - Infra RedGasAnalyser), modelo Li-6400XT (Portable Photosynthesis System - LI) da LICOR.

Foi utilizado um nível de irradiância saturante de 2000 ìmol $\mathrm{m}^{2} \mathrm{~s}^{1}$ de densidade de fluxo de fótons fotossinteticamente ativos (DFFFA), de acordo com teste de curva de luz conforme figura 2 , com temperatura do bloco calibrada a $28^{\circ} \mathrm{C}$, dentro da câmara de medida, que abrange uma área foliar de $6 \mathrm{~cm}^{2}(2 \times 3 \mathrm{~cm})$.

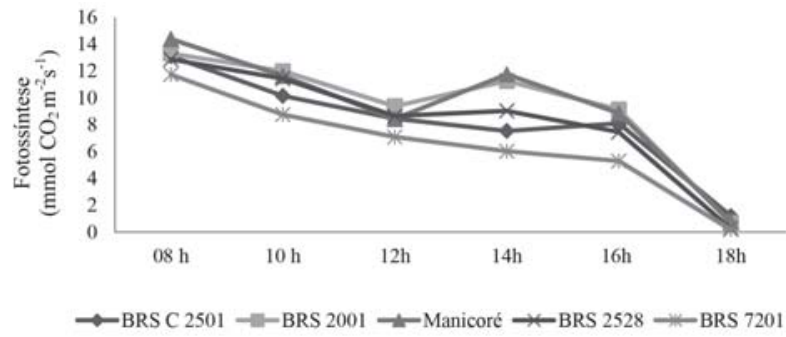

Figura 1 - Curva diária de fotossíntese (A) nos diferentes materiais de dendenzeiro condições de cerrado do Tocantins.

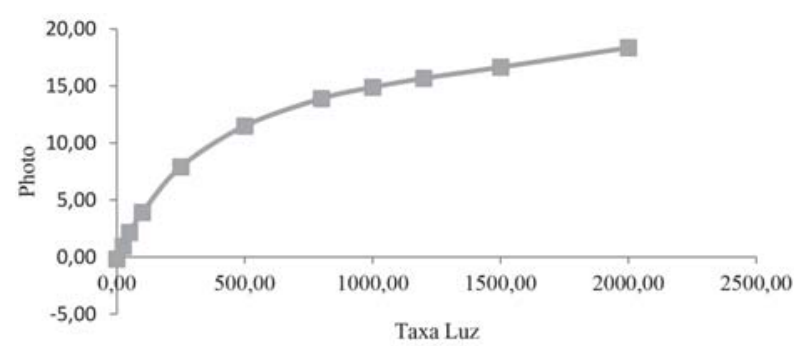

Figura 2 - Curva de luz realizada em plantas de dendezeiro.

As medidas foram realizadas, coletando os seguintes dados: fotossíntese (A), transpiração (E), condutância estomática (gs) e concentração interna de $\mathrm{CO}_{2}(\mathrm{Ci})$. Com os dados de fotossíntese e transpiração foi possível determinar a eficiência instantânea de uso da água (A $\mathrm{E}^{-1}$ ) das plantas de dendezeiro. O delineamento experimental foi em blocos ao acaso, com cinco tratamentos (cultivares híbridos) e dois manejos hídrico (com e sem estresse) e quatro repetições. As respostas obtidas foram comparadas pelo teste Tukey a 5\% de significância utilizando o programa SISVAR 4.2 (Ferreira, 2011).

\section{RESULTADOS E DISCUSSÃO}

A análise de variância para os dados de respostas fisiológicas dos híbridos de dendezeiro indicou que não houve interação para as fontes de variação do presente estudo. Entretanto foi possível observar que houve efeitos isolados significativos para os híbridos (H) e manejo hídrico $(\mathrm{MH})$ para todas as variáveis consideradas neste estudo (Tabela 1).

Foram constatadas diferenças significativas ( $p$ $\leq 0,01$ ), para os efeitos do fator Manejo Hídrico, nas 
variáveis fotossíntese (A) e eficiência do uso da água $\left(\mathrm{AE}^{-1}\right)$. Também houve diferença significativa a 5\% para condutância estomática (gs), concentração de carbono interno (Ci) e transpiração. Em relação ao fator material genético, todas as variáveis analisadas apresentaram significância a $5 \%(\mathrm{p} \leq 0,05)$. As variáveis capacidade fotossintética $\mathrm{A}\left(\mathrm{mmol} \mathrm{CO}_{2} \mathrm{~m}^{-2} \mathrm{~s}^{-1}\right)$ e transpiração $\mathrm{E}$ ( $\mathrm{mol}$ $\left.\mathrm{m}^{-2} \mathrm{~s}^{-1}\right)$ de híbridos de dendezeiro irrigados e sob estresse hídrico estão representadas na Figura 3.

Sob condição irrigada (I) os híbridos Manicoré e BR 2001 apresentaram as maiores taxas fotossintéticas (11,75 e 11,25 $\mathrm{mmol} \mathrm{CO}_{2} \mathrm{~m}^{-2} \mathrm{~s}^{-1}$, respectivamente), diferindo estatisticamente somente do híbrido BRS 7201 (Figura
$01)$, este último com a menor resposta fotossintética $\left(6,02 \mathrm{mmol} \mathrm{CO}_{2} \mathrm{~m}^{-2} \mathrm{~s}^{-1}\right)$. Na condição de estresse hídrico (S.I) os híbridos evidenciaram respostas fotossintéticas semelhantes sem diferenças significativas, com valores correspondentes a 5,02; 5,27;5,33;5,65 e 7,47 mmol $\mathrm{CO}_{2} \mathrm{~m}^{-2} \mathrm{~s}^{-1}$, para os híbridos BRS 2501, BRS Manicoré, BRS 7201, BRS 2001, BRS 2528, respectivamente.

Pelaez et al. (2010) avaliando a fotossíntese máxima em híbridos de dendê, obtiveram valores variando de 8,6 a $10,1 \mathrm{mmol}$ de $\mathrm{CO} 2 \mathrm{~m}^{-2} \mathrm{~s}^{-1}$, enquanto Rivera et al. (2013) encontraram valores entre 9,1 a $14,2 \mathrm{mmol}$ de $\mathrm{CO}_{2} \mathrm{~m}^{-2} \mathrm{~s}^{-1}$. Os quais são semelhantes ao obtidos no presente trabalho, em plantas sem estresse hídrico.

Tabela 1 - Resumo da análise de variância para as variáveis fisiológicas de dendezeiro, submetido à deficiência hídrica. Gurupi - TO, 2015

\begin{tabular}{lcccccc}
\hline \multirow{2}{*}{ FV } & GL & \multicolumn{4}{c}{ Quadrados médios } \\
\cline { 3 - 7 } & & A & Gs & Ci & E & A E-1 \\
\hline Híbridos $(\mathrm{H})$ & 4 & $3,081^{*}$ & $3,525^{*}$ & $5,55^{*}$ & $3,428^{*}$ & $4,248^{*}$ \\
Manejo hídrico $(\mathrm{MH})$ & 1 & $23,904^{* *}$ & $7,258^{*}$ & $6,97^{*}$ & $5,057^{*}$ & $25,67^{* *}$ \\
H*MH & 4 & $2,734^{\text {ns }}$ & $2,267^{\text {ns }}$ & $2,355^{\text {ns }}$ & $1,941^{\text {ns }}$ & $2,014^{\text {ns }}$ \\
Média Geral & & 7,43 & 0,07 & 184,13 & 2,07 & 3,66 \\
\hline
\end{tabular}

FV - Fontes de variação; Híbridos: cinco híbridos testados. Manejo Hídrico - Irrigados e não irrigados; GL - Graus de liberdade; A Fotossíntese (mmol CO $\left.\mathrm{m}^{-2} \mathrm{~s}^{-1}\right)$; gs- Condutância estomática (mol m-2 s-1); CI - Concentração interna de $\mathrm{CO}_{2}$ (ppm de CO2); E - Transpiração

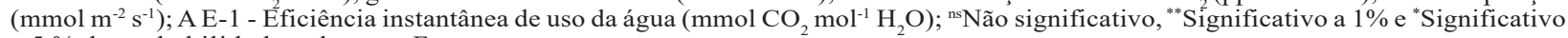
a $5 \%$ de probabilidade pelo teste F.
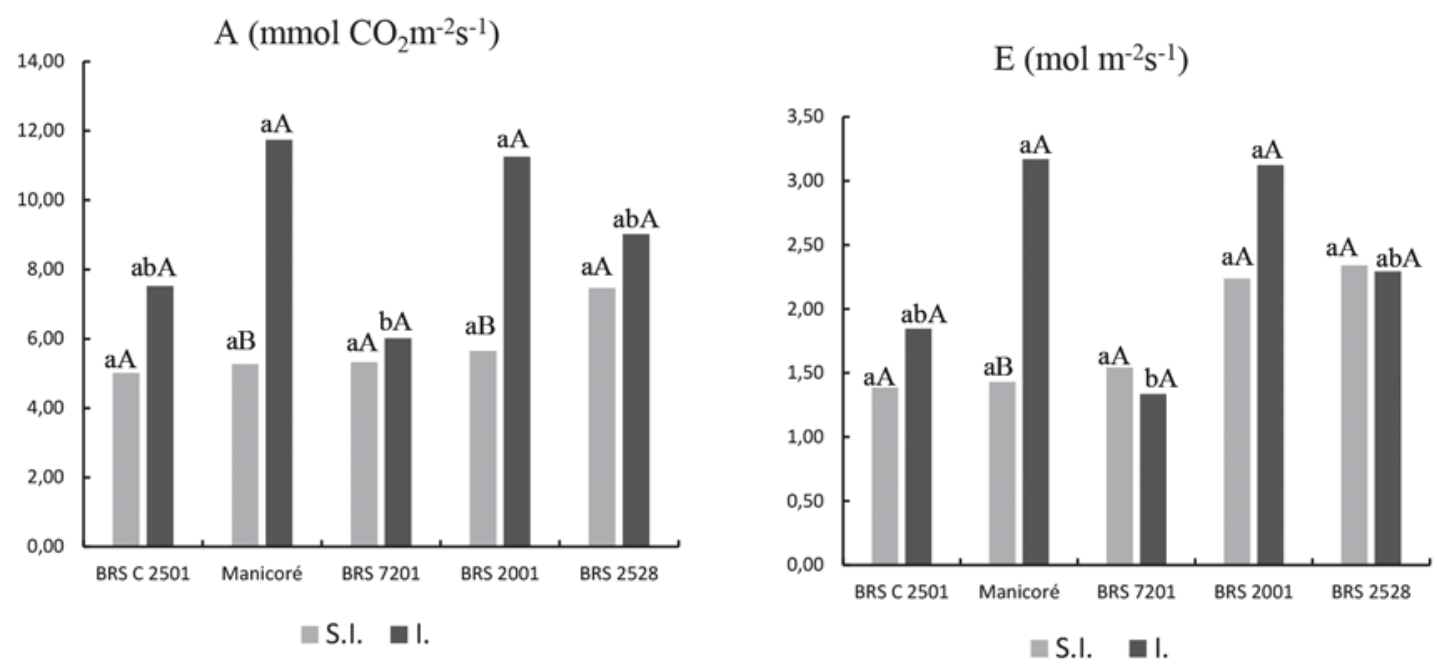

Figura 3 - Fotossíntese líquida (A) e transpiração (E) de híbridos de dendezeiro, sob estresse hídrico (S.I) e irrigada (I). Médias seguidas da mesma letra minúscula entre os híbridos dentro de cada condição de irrigação, e maiúscula entre as condições (irrigado e não irrigado) dentro de híbridos, não diferem estatisticamente pelo teste de Tukey $(\mathrm{p} \leq 0,05)$. 
Bastos (2000) avalia que na ausência a irrigação vem a ser o elemento determinante da disponibilidade de água no solo para uso das plantas, principalmente, nas regiões que não apresentam uma pluviometria regular e suficiente.

A análise acerca do sistema de geração e melhor transferência de energia na planta evidencia a interferência negativa provocada pela falta de água nas plantas de dendê. Uma justificativa para a resposta da queda da taxa fotossintética, no BRS 2001 e o BRS Manicoré, pode corresponder ao processo fisiológico do mecanismo de fechamento dos estômatos das folhas, estratégia que as plantas utilizam não só para reduzir as perdas de água, como também reduzir o suprimento de $\mathrm{CO}_{2}$ para as folhas (Paiva et al., 2005; Taiz e Zeiger, 2009). O Comportamento dos estômatos em dendê tem sido relatado por vários autores, tais como (Pelaez et al., 2010; Rivera et al., 2013) os quais demonstram uma correlação entre o grau de abertura dos estômatos com o conteúdo de água no solo.

A transpiração dos híbridos em função do estresse hídrico (Figura 05), não apresentou diferenças estatísticas entre os materiais BRS 2501, BRS Manicoré, BRS 7201, BRS 2001, BRS 2528 quando os mesmos estavam sob estresse hídrico. Os valores médios correspondentes foram de 1,$39 ; 1,43 ; 1,54 ; 2,24$ e $2,34 \mathrm{~mol} \mathrm{H}_{2} \mathrm{O} \mathrm{m}^{-2} \mathrm{~s}^{-1}$ respectivamente. Já na condição irrigada, o híbrido BRS Manicoré apresentou maior taxa de transpiração, $3,17 \mathrm{~mol} \mathrm{H}_{2} \mathrm{O} \mathrm{m}^{-2} \mathrm{~s}^{-1}$, correspondendo a menor transpiração ao híbrido BRS $7201\left(1,34 \mathrm{~mol} \mathrm{H}_{2} \mathrm{O} \mathrm{m}^{-2} \mathrm{~s}^{-1}\right)$. Ao avaliar os híbridos em ambas as condições irrigado e em seca constata-se que o BRS Manicoré foi o único material genético que diferiu estatisticamente entre as condições, com valores correspondentes a 3,17 e 1,43 $\mathrm{mol} \mathrm{H}_{2} \mathrm{O}$ $\mathrm{m}^{-2} \mathrm{~s}^{-1}$ respectivamente, representando uma redução na transpiração de $43,1 \%$, o que pode indicar ser um material com maior capacidade de redução na perda de água.

A condutância estomática dos híbridos em função do estresse hídrico (Figura 4) apresentou diferenças estatísticas somente na condição irrigada. Os híbridos BRS Manicoré e o BRS 2001 apresentaram os maiores valores de condutância estomática, com valores semelhantes $\left(0,13 \mathrm{~mol} \mathrm{~m}^{-2} \mathrm{~s}^{-1}\right)$. O menor valor correspondeu ao híbrido BRS $7201\left(0,04 \mathrm{~mol} \mathrm{~m}^{-2} \mathrm{~s}^{-1}\right)$. Quando se avalia as condições de irrigação dentro dos híbridos de dendê, constata-se que a semelhança ao observado para a variável fotossíntese somente foram verificadas diferenças significativas nos híbridos Manicoré e BRS 2001. A condutância estomática do híbrido Manicoré sob irrigação correspondeu a $0,13 \mathrm{~mol} \mathrm{~m}^{-2} \mathrm{~s}^{-1}$ enquanto sob estresse hídrico foi de $0,05 \mathrm{~mol} \mathrm{~m}^{-2} \mathrm{~s}^{-1} \mathrm{o}$ que representa uma redução de $61,5 \%$. No caso do BRS 2001 estes valores corresponderam a $0,13 \mathrm{~mol} \mathrm{~m}^{-2} \mathrm{~s}^{-1}$ e $0,07 \mathrm{~mol}$ $\mathrm{m}^{-2} \mathrm{~s}^{-1}$ respectivamente, representando uma redução na condutância estomática de $46,15 \%$.

Analisando a quantidade de carbono intercelular (Ci) dos híbridos de dendê irrigados ou com estresse hídrico (Figura 4), constata-se que todos os híbridos com exceção do Manicoré, apresentaram maiores concentrações de Ci na condição sem irrigação (SI). Porém esta diferença só foi significativa nos híbridos BRS 7201 e BRS 2001. Quando comparados os híbridos na condição sem irrigação (SI) observa-se que o híbrido BRS 2001 apresentou a maior concentração de $\mathrm{Ci}$, se diferindo significativamente somente dos híbridos BRS 2501 e Manicoré. Já na situação de estresse hídrico o híbrido BRS 7201 diferiu dos demais, os menores valores de Ci.

Smith (1989) ao comparar plantas de dendê com e sem irrigação, nas condições do leste da Colômbia, observou que plantas irrigadas possuíam estômatos abertos com maior condutância estomática, porém no presente trabalho, não houve diferenças entre irrigados e sem irrigação para a variável condutância estomática (gs) nos híbridos caiaué BRS Manicoré e do tipo tenera BRS 2001.

Avaliação do funcionamento dos estômatos, em materiais híbridos de dendê comparados a materiais não híbridos, constatou que o processo fotossintético pôde ser realizado por mais tempo durante o dia em materiais híbridos, e se observou nestes híbridos uma maior capacidade de reduzir as perdas de água em condições de seca moderada (Pelaez et al., 2010; Rivera et al., 2013).

A redução da transpiração também pode ser explicada pelo mesmo processo descrito acima, pois na presença de água os estômatos se mantêm abertos e as plantas tem maior capacidade transpiratória, porém em déficit hídrico a resposta é diminuir a perda de água. Embora a redução na taxa de perda de água, mostrado também pela transpiração, possa representar uma vantagem imediata para prevenir a desidratação do tecido, ela pode afetar diretamente o balanço de calor 

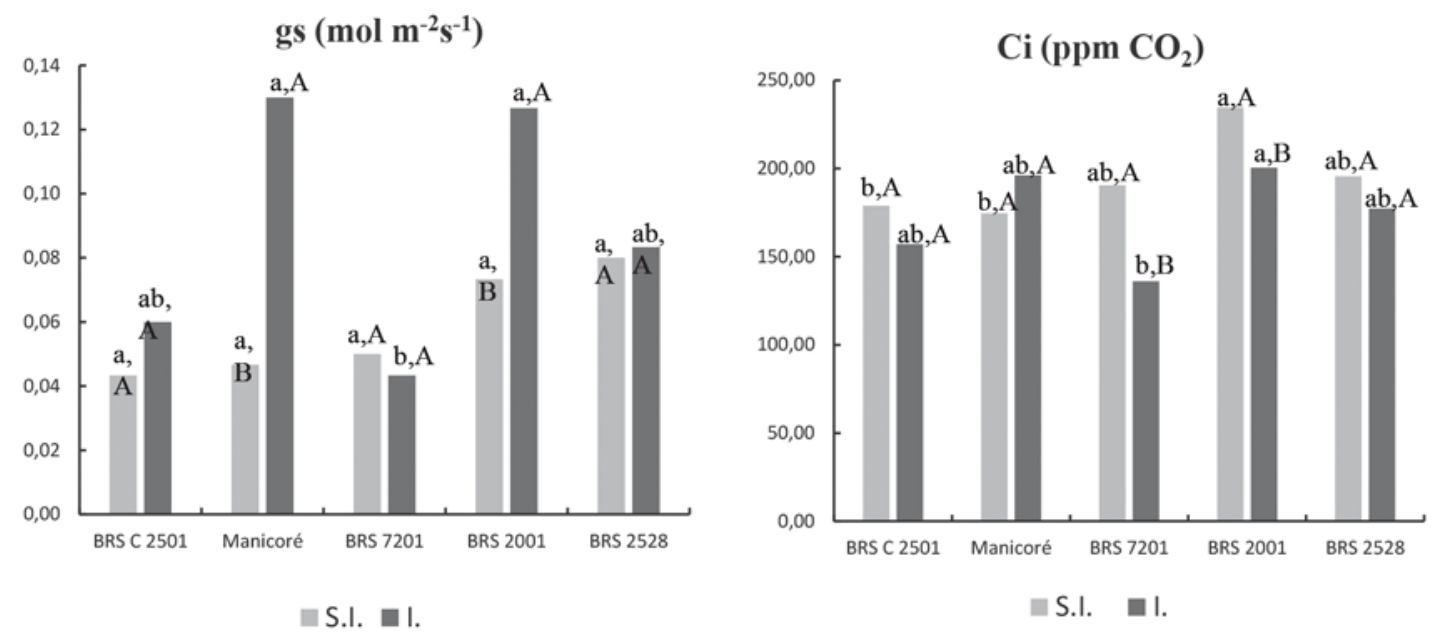

Figura 4 - Condutância estomática (gs) e carbono intercelular (Ci) de híbridos de dendezeiro, sob estresse hídrico (S.I) e irrigada (I). Médias seguidas da mesma letra minúscula entre os híbridos dentro de cada condição de irrigação, e maiúscula entre as condições (irrigado e não irrigado) dentro de híbridos, não diferem estatisticamente pelo teste de Tukey $(\mathrm{p} \leq 0,05)$.

sensível sobre o vegetal, e ainda a absorção de $\mathrm{CO}_{2}$ (Brunini \& Cardoso, 1998).

Mendez (2013) ressaltou em seus trabalhos que os materiais híbridos de dendê, em estresse de seca, têm certa restrição à abertura dos estômatos, porém mesmo assim, as plantas podem ser capazes de manter a fixação de $\mathrm{CO}_{2}$ mesmo com o baixo consumo de água, corroborando assim com os resultados aqui expostos. Segundo Gonçalves (2001) também ajudam a caracterizar o dendê como uma cultura exigente em água, porém pode considerada uma espécie de grande capacidade de sobrevivência nos períodos secos, devido ao seu sistema estomático eficiente e à sua capacidade de restringir a fotossíntese e a mobilização de fotoassimilados aos sítios de reserva, o que vem a resultar em diminuição na produtividade.

Em relação à eficiência no uso da água (figura 5) na condição sem irrigação (SI), ou seja, sob estresse hídrico, observa-se que o Híbrido BRS 2001 foi o que apresentou o menor valor $\left(2,63 \mathrm{mmol} \mathrm{CO}_{2} \mathrm{~mol}^{-1} \mathrm{H}_{2} \mathrm{O}\right)$, porém se diferenciando significativamente somente dos híbridos Manicoré e BRS C 2501, estes últimos apresentando maiores eficiências $(3,65$ e 3,60 mmol de $\mathrm{CO}_{2}$ para cada molécula de água). Quando sob irrigação, os Híbridos BRS 7201 e BRS 2501, apresentaram as maiores eficiências na utilização da água $(4,51 \mathrm{e}$

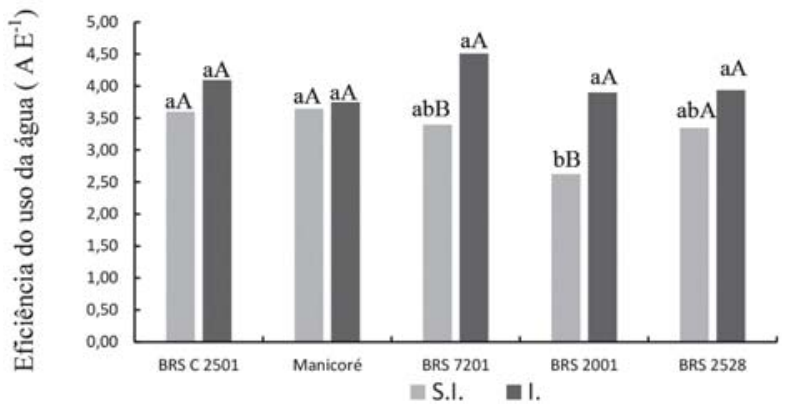

Figura 5 - Eficiência do uso da água $\left(\mathrm{A} \mathrm{E}^{-1}\right)$ de híbridos de dendezeiro, sob estresse hídrico (S.I) e irrigadas (I). Médias seguidas da mesma letra minúscula entre os híbridos dentro de cada condição de irrigação, e maiúscula entre as condições irrigado e não irrigado dentro de híbridos, não diferem estatisticamente pelo teste de Tukey $(\mathrm{p} \leq 0,05)$.

4,09 mmol de $\mathrm{CO}_{2}$ para cada molécula de água, respectivamente). O Híbrido Manicoré teve um comportamento semelhante na eficiência da utilização da água indiferentemente da condição de irrigação imposta.

Os resultados obtidos mostraram que estresse de seca influenciou expressivamente as variáveis 
fisiológicas avaliadas nos híbridos de dendê, principalmente o Manicoré e o BRS 2001.

O efeito da restrição hídrica provocou uma redução na taxa de fotossíntese em todos os híbridos, sendo esta magnitude em ordem decrescente: BRS Manicoré $>$ BRS $2001>$ BRS $2501>$ BRS $2528>$ BRS 7201. Esta resposta foi igual no efeito do estresse hídrico na Condutância estomática (Gs), com exceção do híbrido BRS 7201 que não apresentou redução nas condições sem irrigação. Quando se avalia o efeito do estresse hídrico na Transpiração dos híbridos de dendê, observase uma redução em ordem decrescente: Manicoré > BRS $2001>$ BRS 2501 .

Assim, identifica-se que houve uma relação direta para os híbridos Manicoré; BRS 2001 e BRS C 2501, em relação ao efeito da restrição hídrica, nas variáveis taxa de fotossíntese (A), Condutância estomática (Gs) e Transpiração (E).

Quando em déficit de água, a planta responde com o fechamento dos estômatos para poder reduzir perdas por transpiração, reduzindo simultaneamente o fornecimento de $\mathrm{CO}^{2}$ para a planta, o resultado é uma queda na fotossíntese, conforme resultados aqui obtidos. Esta diminuição pode estar relacionada à abertura dos estômatos, uma vez que estes são pontos de controle de vapor d'água e balanço de energia entre o vegetal e o ambiente. Assim de uma maneira geral, uma diminuição nos valores menos acentuada de A, gs e E destacam uma vantagem ecológica que as plantas obtêm ao variar tais parâmetros, principalmente no caso da fotossíntese é manter uma relação linear com a eficiência do uso da água, otimizando assim, as trocas gasosas (Schulze \& Hall, 1982).

\section{CONCLUSÕES}

Os híbridos BRS Manicoré e BRS 2001 são os materiais que apresentam maiores reduções nas variáveis fisiológicas avaliadas, quando sob condição de estresse hídrico. Nas condições que foi desenvolvido o trabalho pode se considerar que os híbridos BRS 2501 e BRS 2528 , são os mais eficientes fisiologicamente nas condições de estresse. Os cinco híbridos avaliados reduzem drasticamente a fotossíntese líquida sob condição de estresse de seca com a restrição hídrica. O BRS 7201 apresenta maior eficiência no controle da perda de água pela transpiração sob condições de estresse hídrico.

\section{LITERATURA CITADA}

AZEVEDO, J. A.; JUNQUEIRA, N. T. V.; BRAGA, $M$. F. et al. Parâmetros de irrigação durante o período seco em plantas jovens de dendê cultivadas no Cerrado. Planaltina, DF: Embrapa Cerrados, 2008. 4p. (Embrapa Cerrado: Comunicado Técnico, 146).

BASTOS, T. X. Aspectos agroclimáticos do dendezeiro na Amazônia Oriental. In: Viégas, I. J. M.; Müller, A. A. (Ed.). A cultura do dendezeiro na Amazônia Brasileira. Belém: Embrapa Amazônia Oriental; Manaus: Embrapa Amazônia Ocidental, 2000. p. 47-59.

BRUNINI, O.; CARDOSO, M. Efeito do déficit hídrico do solo sobre o comportamento estomático e potencial da água em mudas de seringueira. Pesquisa Agropecuária Brasileira, v.33, n.7, p.1053-1060, 1998.

CHIA, G. S.; LOPES, R; CUNHA, R.N.V. et al. Repetibilidade da produção de cachos de híbridos interespecíficos entre o caiaué e o dendezeiro. Acta Amazônica, v.39, n.2, p.249-254, 2009.

CHIA, G. S.; LOPES, R; CUNHA, R.N.V et al. Gene sh e ginandromorfia em inflorescências masculinas de híbridos F1 entre o caiaué e o dendê. Revista de Ciências Agrárias, v. 55, n.3, p. 212-219, 2012.

FERREIRA, D.F. Sisvar: um sistema computacional de análise estatística. Ciência agrotecnologia, v.35 n.6, p. 1039-1042, 2011.

GOMES JÚNIOR, R.A.; PINA, A.J.A.; GURGEL, F.L. et al. Sistema de produção de mudas em híbridos interespecíficos entre caiaué e dendê. Ciência Florestal, v. 27, n. 1, p. 169-179, 2017.

GONÇALVES, A.C.R. Dendezeiro (Elaeis guineensis Jacq.). In: Castro, P. R. C.; Kluge, R.

A. (Eds.). Ecofisiologia de culturas extrativas: cana-de-açúcar, seringueira, coqueiro, dendezeiro e oliveira. Cosmópolis: Stoller do Brasil, 2001. p. 95-112. 
MACIEL, F.C.S.; CORDEIRO, A.A.C.; CORREIA, R.G. et al. Desenvolvimento vegetativo da palma de óleo em ecossistemas de savana e floresta de Roraima. Revista Agro@mbiente Online, v.5, n.3, p.194-199, 2011.

MENDEZ, Y.D.R. CAYON, D.G.S.; LOPEZ, J.E et al. Physiological and morphological characterization of american oil palms (Elaeis oleiferaHBK Cortes) and their hybrids (Elaeis oleifera $\times$ Elaeis guineensis) on the Indupalma plantation. Agronomía Colombiana, v.3, n.3, p.314323, 2013.

MENDEZ, Y.D.R.; CAYON, D.G.S.; LOPEZ, J.E. Physiological and morphological characterization of American oil palms (Elaeis oleifera HBK Cortes) and their hybrid (Elaeisoleifera $\times$ Elaeisguineensis) on the Indupalma plantation. Agronomía Colombiana, v. 31, n.3, 314323, 2013.

MOURA, J.I.L.; ; SANTOS, L.P.; BITTENCOURT, M.A.L. et al. Preferência do bicudo-das-palmeiras por dendezeiro, caiaué e por seu híbrido interespecífico. Pesquisa agropecuária brasileira, v.48, n.4, p.454-456, 2013.

NOGUEIRA, R.J.M.C.; MORAES, J.A.P.V.; BURITY, H.A. et al. Alterações na resistência à difusão de vapor das folhas e relações hídricas em aceroleiras submetidas a déficit de água.

Revista Brasileira de Fisiologia Vegetal, v. 13, n. 01, p. 75-87, 2001.

PAIVA, A.S.; FERNANDES, E.J.; RODRIGUES, T.J.D. et al. Condutância estomática em folhas de feijoeiro submetido a diferentes regimes de irrigação. Revista Brasileira de Engenharia Agrícola, v. 25, n. 01, p. 161$169,2005$.
PASSOS, E.E.M.; PASSOS, C.D; PRADO, C.H.B. Comportamento sazonal do potencial hídrico e das trocas gasosas de quatro variedades de coqueiroanão. Aracaju, Embrapa Tabuleiros Costeiros, 2006. 19p. (Boletim de Pesquisa e Desenvolvimento, 18)

PELAEZ, E.E.; RAMÌREZ, D.P; CAYON, D.G. Fisiologia comparada de palmas africana (Elaeis guineenses Jacq.), americana (Elaeis oleífera H.B.K. Cortes) e hibridos (Elaeis oleífera x Elaeis guineensis) en Hacienda La Cabana. Revista Palmas, v.31, n.2, 29-38. 2010.

QUEIROZ, A.G.; FRANÇA, L.; PONTES, M.X. The life cycle assessment of biodiesel from palm oil ("dende") in the Amazon. Biomass and bioenergy, v.36, p.50-59, 2012.

SCHULZE, E.D.; HALL, A.E. Stomatal responses, water loss and $\mathrm{CO}_{2}$ assimilation rate in contrasting environments. In: O.L. Lange, P.S. Nober, C.B.

Osmond \& H. Ziegler (eds.). Encyclopedia of plant physiology, v. 12B, Physiological plant ecology. II. Water relations and carbon assimilation. Springer Verlag, Berlin, pp.181-230. 1982

SMITH, B.G. The Effects of Soil Water and Atmospheric Vapour Pressure Deficit on Stomatal Behaviour and Photosynthesis in the Oil Palm.

Revista Ciência e Agrotecnologia, v.33, n.2, p.647651, 1989.

TAIZ, L; ZEIGER, E. Fisiologia vegetal. 4. ed. Porto Alegre: Artmed, 2009. 819 p.

TEIXEIRA, H.S.R.; RODRIGUES, H. S.; LIMA, W. A. A. et al. Influência da disposição dos tubetes e da aplicação de fertilizantes de liberação lenta, durante o pré-viveiro, no crescimento de mudas de dendezeiro (elaeis guineensis jacq.). Ciência Florestal, v.19, n.2, p.157-168, 2009.

Recebido para publicação em 4/7/2018 e aprovado em 2/12/2018. 